\title{
Life history characteristics of fjord-dwelling golden king crabs Lithodes aequispina
}

\author{
N. A. Sloan \\ Department of Fisheries and Oceans, Fisheries Research Branch, Pacific Biological Station, Nanaimo, British Columbia, \\ Canada V9R 5 K6
}

\begin{abstract}
In an interconnecting system of silled, narrow, steep-walled fjords in northern British Columbia (Canada) 3800 golden king crab Lithodes aequispina Benedict and 184 red king crab Paralithodes camtschatica (Tilesius) were taken between 51 to $569 \mathrm{~m}$ in 3 samples over a 10 mo period. Larval retention within the most isolated fjords is suggested as an explanation for the relatively high numbers of $L$ aequispina and the relatively high $(41.0 \%)$ infection level of the crabs by the castrating rhizocephalan barnacle parasite Briarosaccus callosus Boschma. Life history characteristics of king crab species in fjords are related to depth. The normaly continental shelf- and slope-dwelling $L$. aequispina were found significantly deeper than the characteristically intertidal to continental shelf dwelling $P$. camtschatica. Depth stratification of $L$. aequispina was related to reproductive state among unparasitized crabs and parasitism by $B$. callosus of the others. Reproduction of unparasitized $L$. aequispina was continuous and aseasonal. Coexisting female $P$. camtschatica displayed strong synchronous reproduction characteristic of the species elsewhere. I propose that juvenile female $L$. aequispina recruit in the shallows (usually $<100 \mathrm{~m}$ ). Females mate and extrude eggs at usually $<150 \mathrm{~m}$ and incubate eggs slightly deeper $(\approx 150$ to $250 \mathrm{~m})$. Spawned out (matted setae) females dominate the unparasitized female population at $>200 \mathrm{~m}$ and comprise the largest proportion of unparasitized females overall. This last phase may exceed a year in length and is probably followed by upward migration to the level $(50$ to $150 \mathrm{~m}$ ) at which the less migratory unparasitized adult males are most abundant. Parasitized male and female L. aequispina behave like matted setae females and are the largest component of the total crab population from 200 to $400 \mathrm{~m}$.
\end{abstract}

\section{INTRODUCTION}

The golden king crab Lithodes aequispina Benedict is a little known, deep-water North Pacific anomuran crab. A fishery for $L$. aequispina has recently developed in fjords and trenches off southeast Alaska (T. Koeneman pers. comm.) and along continental slopes of the eastern Bering Sea and Aleutian Islands (Otto et al. 1983). This development has been stimulated by marked stock declines of the comparatively shallow-water red king crab Paralithodes camtschatica (Tilesius) (Armstrong 1983). L. aequispina also occurs off the west coast of Vancouver Island north of $49^{\circ} \mathrm{N}$ (Butler \& Hart 1962), on Gulf of Alaska seamounts (Hughes 1981), on the continental shelf and slope of the Okhotsk Sea, west of Kamchatka (Rodin 1970) and in deep bays off the central east coast of Honshu (Hiramoto \& Sato 1970, Suzuki \& Sawada 1978), although apparently not in commercial quantities at any of these localities.
I report here on some life history characteristics of fjord-dwelling golden king crab Lithodes aequispina from 51 to $569 \mathrm{~m}$ in fjords within the Portland Inlet system of northern British Columbia. Emphasis is placed on reproduction and vertical distribution of $L$. aequispina in the narrow, steep-sided fjords. These characteristics are compared with those of other Lithodes spp. Comparative data on coexisting red king crab Paralithodes camtschatica are also provided and discussed.

\section{STUDY SITE}

The Portland Inlet system is a group of deep, interconnected fjords at the extreme northern end of the British Columbia coast (Fig. 1A). The steep-sided basins of the fjords are partially isolated by sills as minimum sill depths range from $25 \mathrm{~m}$ for Alice Arm, $55 \mathrm{~m}$ for Hastings Arm, $46 \mathrm{~m}$ for Observatory Inlet at its south end and $21 \mathrm{~m}$ for Work Channel (Fig. 1B). Port- 

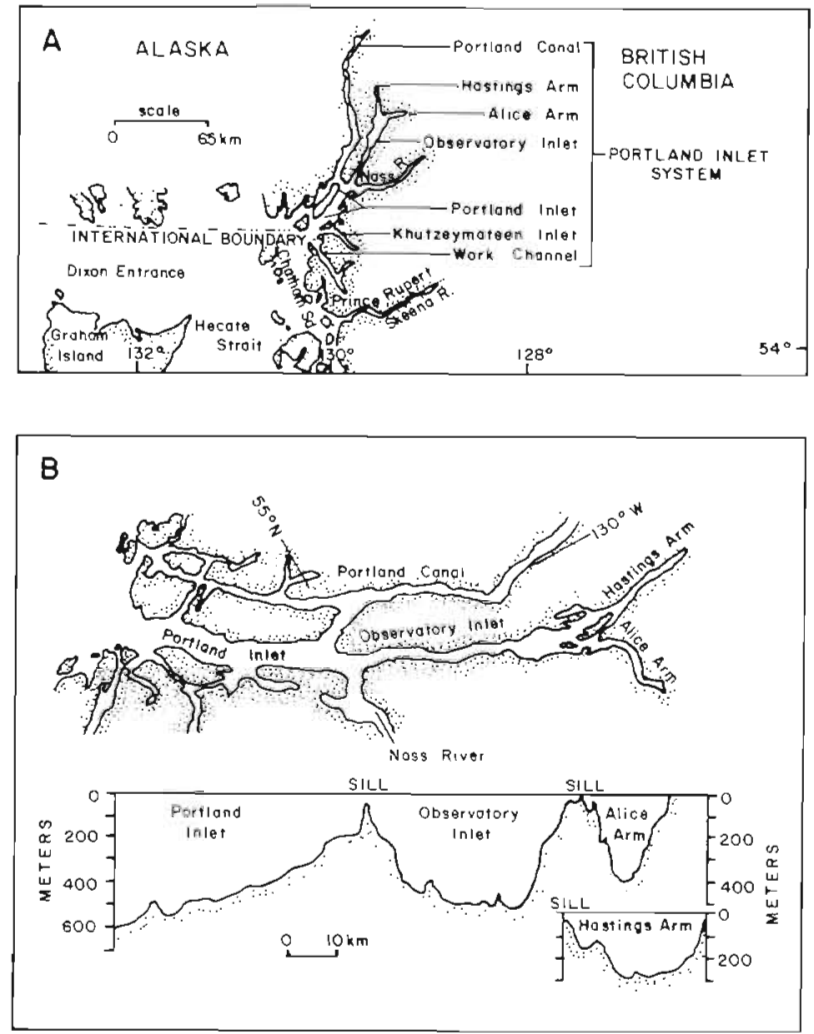

Fig. 1. (A) Portland Inlet system, northern British Columbia. Component fjords; (B) longitudinal depth profile showing position and depth of sills in Observatory Inlet, Hastings Arm and Alice Arm (after D. J. Stucchi)

land Inlet has a deep $(180 \mathrm{~m})$ sill outside the Inlet proper at the eastern end of Dixon Entrance (Pickard 1961, D. J. Stucchi pers. comm.). Observatory Inlet thus has sills at both its ends. The level bottoms of all fjords are characterized by soft sediment, similar to other deep N. E. Pacific fjords (Cimberg 1982, Levings et al. 1983).

\section{MATERIALS AND METHODS}

A total of 390 single king crab pot sets and 45 Tanner crab pot sets (35 of these being paired pots) were made throughout the deep troughs of 5 fjords in the Portland Inlet system over 3 sampling periods (Oct/Nov 1983; Feb/Mar 1984; Jul 1984). The depth and soak time of each pot were recorded. Approximately $68.0 \%$ of the sampling effort occurred in Alice Arm (see Table 1 for details).

Alaskan side-entry king crab pots measuring $1.8 \times 1.8 \times 0.9 \mathrm{~m}$ and covered with $9.0 \times 12.0 \mathrm{~cm}$ mesh were used. Pots had 2 tunnels each with $88.0 \times 19.0 \mathrm{~cm}$ openings or 'tunnel eyes'. Each pot was baited with two $2 \mathrm{l}$, perforated jars of chopped frozen herring. The tapered, rectangular Tanner crab pots measured
$1.1 \times 1.1 \mathrm{~m}$ at the base, $0.7 \mathrm{~m}$ high and $0.7 \times 0.7 \mathrm{~m}$ at the top and were covered with $5.0 \times 5.0 \mathrm{~cm}$ mesh. There was a single top opening with a fibreglass tunnel of $33.0 \times 33.0 \mathrm{~cm}$ that tapered to $18.0 \times 18.0 \mathrm{~cm}$. Each Tanner pot was baited with one 21 jar of chopped frozen herring.

Captured Lithodes aequispina were measured for carapace length and right cheliped height (subsample of males only) to the nearest mm (Wallace et al. 1949) and weighed to the nearest $0.05 \mathrm{~kg}$ (1983 sample only). Crabs were noted for missing or regenerating limbs and individuals with those conditions were not weighted. Shell class was noted as either: (1) for crabs that had moulted recently, i.e. clean, light-colored exoskeleton showing little abrasion, or (2) for other crabs, discolored, abraded exoskeletons with epizooites. Sex and carapace length of Paralithodes camtschatica were also recorded.

Crabs were examined for the presence of the rhizocephalan barnacle parasite Briarosaccus callosus Boschma, externae or their remaining scars, especially on the ventral abdomen surface. A random subsample of externae was examined to establish whether parasites differed from hosts in reproductive synchronization. Externae were slit open and observed, using a microscope, for condition of eggs or larvae in the mantle cavity. Development stages were: 0 , if the mantle cavity was empty; 1, if eggs were present but unhatched; 2, if fewer than half the eggs had hatched (into nauplii); 3 , if more than half the eggs had hatched (Bower \& Sloan 1985).

Sexual maturities of unparasitized female Lithodes aequispina and Paralithodes camtschatica were classified as juvenile (no eggs nor their remnants on pleopod setae), egg-bearing (eggs attached to pleopods) or matted setae (post-spawned condition in which pleopods have long entangled setae sometimes bearing egg remnants). For unparasitized males, size at sexual maturity was calculated with Somerton's (1980) method (Jewett at al. 1985) using the relation between carapace length and right cheliped height. All males $\leq 114 \mathrm{~mm}$ carapace length were classified as juvenile.

\section{RESULTS}

\section{Sampling effort and catch}

Sampling effort, depths and catches are listed according to cruise date and fjord in Table 1 . A total of 470 pots were deployed in 51 to $569 \mathrm{~m}(\overline{\mathrm{x}}=230 \mathrm{~m})$ for soak times ranging between 5.5 and $96.8 \mathrm{~h}$ $(\overline{\mathrm{x}}=31.5 \mathrm{~h})$. Sampling was deepest in Observatory Inlet with a mean pot depth of $409 \mathrm{~m}$. The total catch was 3800 Lithodes aequispina, 184 Paralithodes 
Table 1. Lithodes aequispina. Sampling effort, depths, catch, and catch per unit effort of king crabs in fjords within the Portland Inlet system

\begin{tabular}{|c|c|c|c|c|c|c|c|}
\hline \multirow[t]{2}{*}{ Cruise dates } & \multirow[t]{2}{*}{ Fjord } & \multirow{2}{*}{$\begin{array}{c}\text { No. of } \\
\text { pot sets }\end{array}$} & \multirow{2}{*}{$\begin{array}{l}\text { Sampling effort } \\
\text { (hours of } \\
\text { soak time) }\end{array}$} & \multicolumn{2}{|c|}{ Pot depths (m) } & \multicolumn{2}{|c|}{ Catch $\left(\mathrm{CPUE}^{2}\right)$} \\
\hline & & & & $\bar{x}$ & Range & L. aequispina & P. camtschatica \\
\hline $\begin{array}{l}\text { Oct } 27-\text { Nov } 6 \\
1983\end{array}$ & $\begin{array}{l}\text { Alice Arm } \\
\text { Hastings Arm } \\
\text { Observatory Inlet } \\
\text { Portland Inlet }\end{array}$ & $\begin{array}{l}44 \\
44 \\
31 \\
31\end{array}$ & $\begin{array}{r}1434 \\
1465 \\
1076 \\
732\end{array}$ & $\begin{array}{l}261 \\
253 \\
409 \\
335\end{array}$ & $\begin{array}{r}93-382 \\
82-315 \\
110-569 \\
205-439\end{array}$ & $\begin{aligned} 1032 & (0.72) \\
258 & (0.18) \\
104 & (0.10) \\
2 & (<0.01)\end{aligned}$ & $\begin{aligned} 65 & (0.05) \\
7 & (<0.01) \\
0 & \\
0 & \end{aligned}$ \\
\hline $\begin{array}{l}\text { Feb 24-Mar 5, } \\
1984\end{array}$ & $\begin{array}{l}\text { Alice Arm } \\
\text { Hastings Arm } \\
\text { Work Channel }\end{array}$ & $\begin{array}{l}98 \\
34 \\
19\end{array}$ & $\begin{array}{r}4675 \\
1000 \\
460\end{array}$ & $\begin{array}{l}109 \\
291 \\
233\end{array}$ & $\begin{array}{r}51-402 \\
165-318 \\
53-318\end{array}$ & $\begin{aligned} 1484 & (0.32) \\
165 & (0.17) \\
0 & \end{aligned}$ & $\begin{aligned} & 17(<0.01) \\
& 0 \\
& 0\end{aligned}$ \\
\hline $\begin{array}{l}\text { Jul 20-30, } \\
1984\end{array}$ & $\begin{array}{l}\text { Alice Arm } \\
\text { Total }\end{array}$ & $\begin{array}{l}134^{3} \\
435^{3}\end{array}$ & $\begin{array}{r}3956 \\
14799\end{array}$ & $\begin{array}{l}221 \\
230\end{array}$ & $\begin{array}{l}59-399 \\
51-569\end{array}$ & $\begin{array}{l}755(0.19) \\
3800(0.26)\end{array}$ & $\begin{array}{r}95(0.02) \\
184(0.01)\end{array}$ \\
\hline $\begin{array}{l}{ }^{1} \text { Single king } \mathrm{cr} \\
{ }^{2} \mathrm{CPUE}=\mathrm{catcl} \\
{ }^{3} \text { Includes } 45 \mathrm{Ta}\end{array}$ & $\begin{array}{l}\text { pot sets unless o } \\
\text { er unit effort (cra) } \\
\text { ner crab pot sets, }\end{array}$ & $\begin{array}{l}\text { wise spec } \\
-1 \text { soak tir } \\
\text { hich } 35 \text { se }\end{array}$ & $\begin{array}{l}\text { ed } \\
\text { were paired po }\end{array}$ & & & & \\
\hline
\end{tabular}

camtschatica, and 2721 brachyuran Tanner crabs Chionoecetes bairdi Rathbun. Tanner crabs occurred in $>80 \%$ of the pots in all fjords and at all depths. On the first cruise sampling effort was similar in Alice Arm and Hastings Arm although the catch of L. aequispina in Alice Arm was 4 times greater. Catch per unit effort

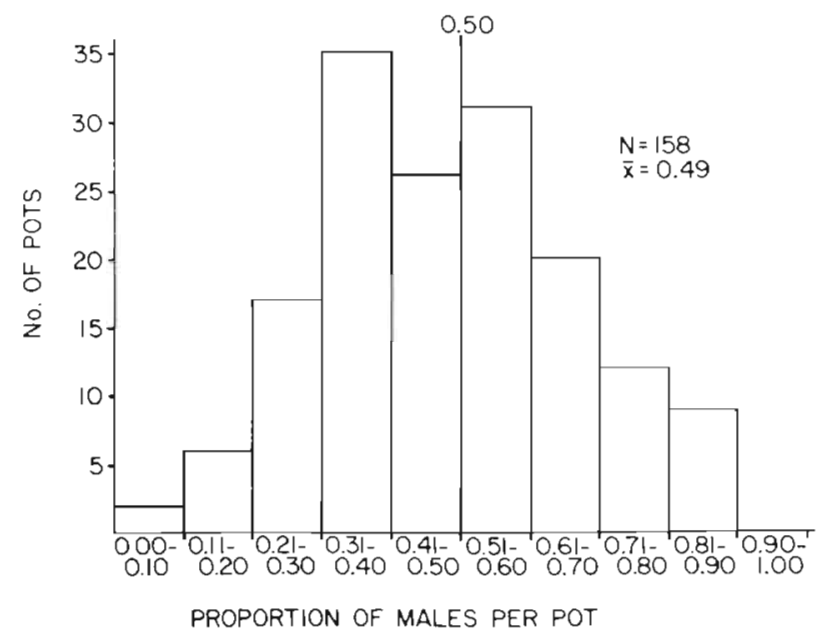

Fig. 2. Lithodes aequispina. Histogram illustrating frequency of proportions of males per pot in pots with $\geq 10$ crabs in the Portland Inlet system

in Observatory Inlet was even less than in Hastings Arm, extremely low in Portland Inlet and no L. aequispina were taken in Work Channel. By-catch of halibut Hippoglossus stenolepis (Schmidt) was highest in Portland Inlet (in $62 \%$ of pots), lower in Observatory Inlet (in $35 \%$ of pots) and lowest in Alice and Hastings Arms (in $<5 \%$ of pots). P. camtschatica were caught only in
Alice and Hastings Arms where the catch was $<5.0 \%$ of the $L$. aequispina catch.

\section{Sex ratios}

Males comprised $48.8 \%(n=1854)$ of Lithodes aequispina, whereas $35.8 \%(n=66)$ of Paralithodes camtschatica captured were males. Fig. 2 illustrates the frequency distribution of the proportion of male $L$. aequispina per pot for the 158 pots which yielded $\geqslant 10$ golden king crabs. Proportions of males ranged widely (0.09 to 0.90) but were normally distributed (ShapiroWilk test; $\mathrm{p}<0.01$ ) about the mean of 0.49 . Among just the unparasitized adult $L$, aequispina, however, a depth-related trend in sex ratio is described below.

\section{Parasites and associates}

Infection by the rhizocephalan parasite Briarosaccus callosus occurred in $41.0 \%(n=1558)$ of the Lithodes aequispina among which $49.1 \%(n=756)$ of the hosts were males. Only one Paralithodes camtschatica (a female) was parasitized. None of the 803 parasitized female crabs bore eggs. $B$. callosus probably sterilizes the crabs it infects (Bower \& Sloan 1985) and certainly retards growth of male, although not female, hosts (Sloan 1985).

Adults, and deposited cocoons, of the sanguivorous fish leech Notostomum cyclostoma (Johansson) were commonly found on all crab species, especially $L$. aequispina, but caused them no harm (Sloan et al. 1984). 


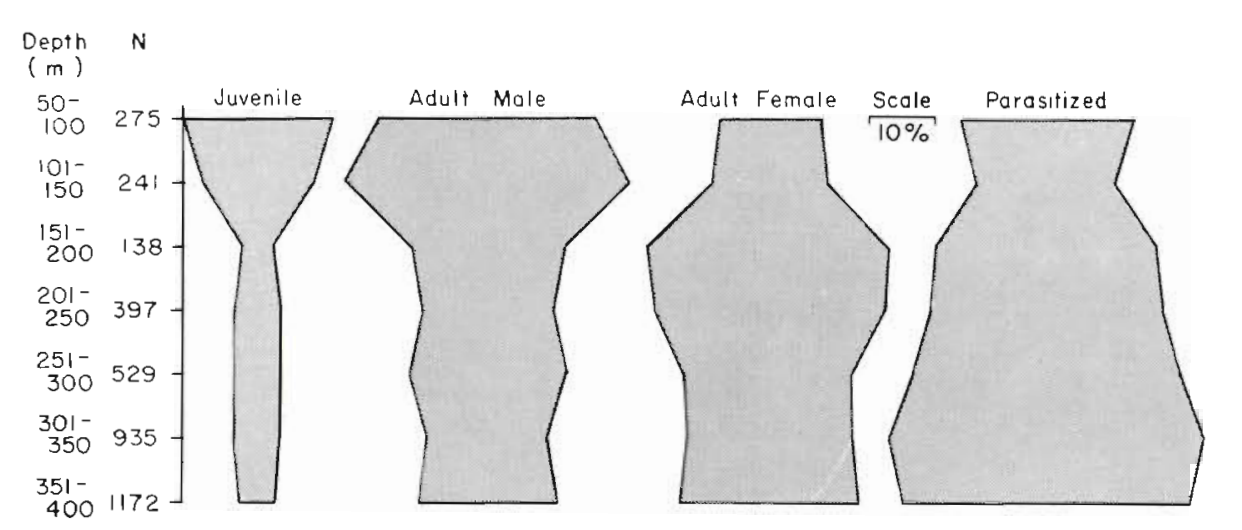

\section{Depth preferences}

In Alice and Hastings Arms, where the 2 king crab species were found together, the mean depth at which the 3694 Lithodes aequispina were caught was $272 \mathrm{~m}$ (range 51 to $402 \mathrm{~m}$ ), that for the 184 Paralithodes camtschatica $114 \mathrm{~m}(59-384 \mathrm{~m})$. Only 6 P. camtschatica were taken deeper than $150 \mathrm{~m}$ : a female at $159 \mathrm{~m}$ and 5 males between 183 and $384 \mathrm{~m}$.

The distribution of juvenile, adult and parasitized Lithodes aequispina according to depth in all fjords (to $400 \mathrm{~m}$ ) is shown in Fig. 3. The deeper pots (401 to $569 \mathrm{~m}$ ) are excluded here because only one (yield of 16 crabs at $402 \mathrm{~m}$ ) occurred outside Observatory Inlet whose $L$. aequispina had a very low infection rate $(2.9 \%)$ of Briarosaccus callosus (Sloan 1985). Proportions of juvenile $L$. aequispina were maximum at 50 to $100 \mathrm{~m}$, adult males at 101 to $150 \mathrm{~m}$, adult females at 151 to $250 \mathrm{~m}$ and parasitized crabs at 251 to $400 \mathrm{~m}$. Approximately $68.4 \%$ of all unparasitized $L$. aequispina between 50 and $150 \mathrm{~m}$ were males, whereas females comprised $57.4 \%$ of all unparasitized crabs between 301 and $400 \mathrm{~m}$.

\section{Crab sizes}

Table 2 lists the means and ranges of carapace lengths of unparasitized Lithodes aequispina and

Table 2. Lithodes aequispina and Paralithodes camtschatica. Carapace lengths of unparasitized king crabs from Alice and Hastings Arms in the Portland Inlet systern

\begin{tabular}{|clrrrr|}
\hline Species & & & \multicolumn{3}{c|}{$\begin{array}{c}\text { Carapace length } \\
\text { (mm) }\end{array}$} \\
\hline Lithodes & Sex & $\mathrm{n}$ & $\overline{\mathrm{x}}$ & Range \\
$\begin{array}{c}\text { aequispina } \\
\text { Paralithodes } \\
\text { camtschatica }\end{array}$ & Male & 1089 & 140.8 & $62-192$ \\
& Memale & 1153 & 124.5 & $59-174$ \\
& Female & 117 & 124.9 & $82-170$ \\
\hline
\end{tabular}

Fig. 3. Lithodes dequispina. Distribution of proportions of juveniles, adult males, adult females, and parasitized crabs $(\mathrm{n}=3687)$ according to depths (50 to $400 \mathrm{~m}$ ) in the Portland Inlet system. Scale bar: $10 \%$ of population
Paralithodes camtschatica. The females of both species were similar in size, although smaller than male conspecifics. Male $L$. aequispina were larger than male $P$. camtschatica. The largest male and female $L$. aequispina weighed $5.15 \mathrm{~kg}$ and $3.05 \mathrm{~kg}$ respectively. Both were unparasitized and both came from $476 \mathrm{~m}$ in Observatory Inlet. The carapace length-body weight relations for unparasitized $L$. aequispina from the 1983 cruise were estimated by fitting lines to log-transformed data (illustrated in Sloan 1985) and characterized by the power curve formulae:

Male body weight $=2.8\left(\times 10^{-7}\right)$ carapace length $^{3.17}$ $\left(\mathrm{r}^{2}=.97 ; \mathrm{n}=326\right)$

Female body weight $=19.4\left(\times 10^{-7}\right)$ carapace length ${ }^{2.75}\left(r^{2}=.95 ; n=396\right)$.

There were some between-fjord differences in body size of Lithodes aequispina listed in Table 3. The carapace lengths of both male and female unparasitized $L$. aequispina from Observatory Inlet in the first cruise were significantly larger (Student's t-tests; $0.01<p<0.001$ ) than those of males or females from either Alice Arm or Hastings Arm. The carapace lengths of unparasitized $L$. aequispina from Alice and Hastings Arms, combined from the first 2 cruises, revealed that the males from Hastings Arm were slightly larger than males from Alice Arm (Student's t-test $p<0.05$ ). Female $L$. aequispina from Hastings Arm were no different in size than females from Alice Arm (Student's t-test; $\mathrm{p}>0.05$ ).

The mean carapace lengths of unparasitized adult Lithodes aequispina varied little (142.3 to $144.9 \mathrm{~mm}$ ) according to depth at $50 \mathrm{~m}$ intervals between 50 and $400 \mathrm{~m}$. If, however, the sizes of juveniles were included, the mean sizes at the 50 to $100 \mathrm{~m}$ and 101 to $150 \mathrm{~m}$ depth levels were significantly smaller (Student's t-tests; $\mathrm{p}<0.01$ ) than those of just the adult samples because of the relatively large proportion of juveniles at 50 to $150 \mathrm{~m}$, illustrated in Fig. 3 .

Histograms of carapace lengths according to different reproductive stages of unparasitized female Lithodes aequispina are illustrated in Fig. 4. Juveniles 
Table 3. Lithodes aequispina. Carapace lengths of unparasitized males and females according to fjord in the Portland Inlet system. Cruise I $=$ Oct/Nov, 1983; Cruise II = Feb/Mar, 1984

\begin{tabular}{|c|c|c|c|c|c|}
\hline \multirow[t]{2}{*}{ Fjord } & \multirow[t]{2}{*}{ Cruise number } & \multicolumn{2}{|c|}{$\begin{array}{c}\text { Male L. aequispina } \\
\text { Carapace length }(\mathrm{mm})\end{array}$} & \multicolumn{2}{|c|}{$\begin{array}{l}\text { Female L. aequispina } \\
\text { Carapace length }(\mathrm{mm})\end{array}$} \\
\hline & & $\mathrm{n}$ & $\overline{\mathrm{x}} \pm \mathrm{SD}$ & $\mathrm{n}$ & $\overline{\mathrm{x}} \pm \mathrm{SD}$ \\
\hline Observatory Inlet & I & 61 & $154.7 \pm 18.7$ & 40 & $141.6 \pm 19.2$ \\
\hline Hastings Arm & I \& II & 125 & $143.8 \pm 26.1$ & 126 & $122.3 \pm 18.4$ \\
\hline Alice Arm & I \& II & 541 & $140.5 \pm 16.7$ & 684 & $124.4 \pm 11.9$ \\
\hline
\end{tabular}

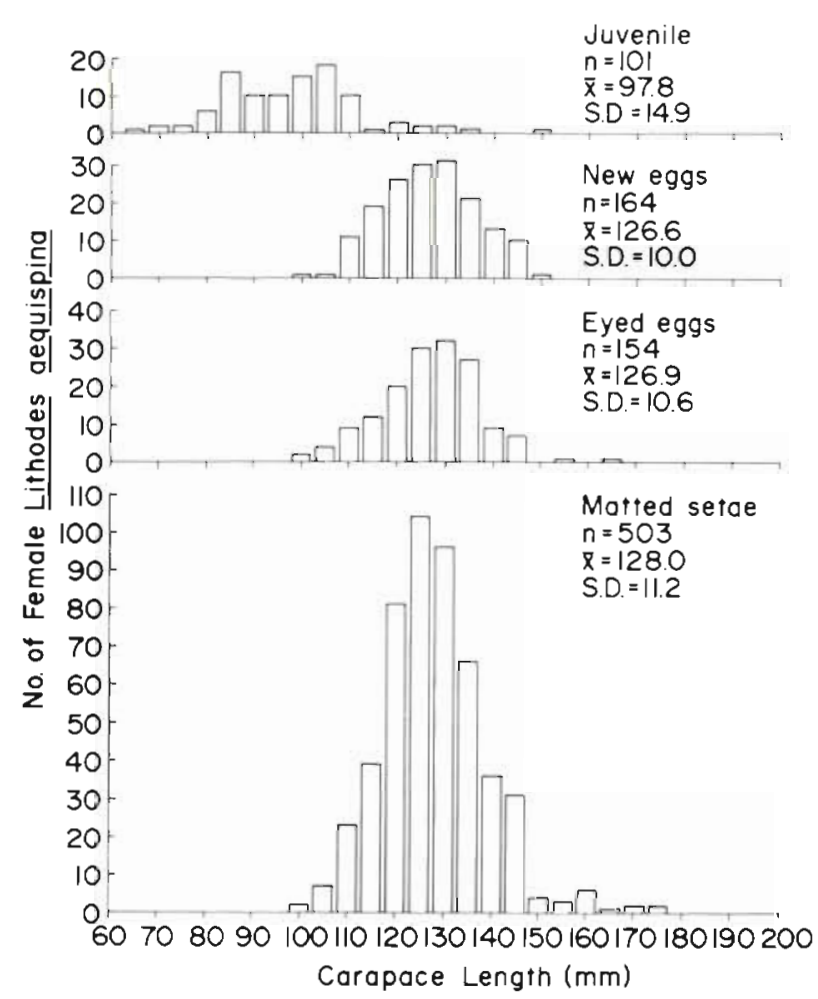

Fig. 4. Lithodes aequispina. Histograms of carapace-length size classes of 922 unparasitized females according to different maturity stages from juvenile to matted setae were significantly smaller (Student's t-test; $\mathrm{p}<0.001$ ) than egg-bearing or matted setae females. No size differences occurred among the 3 classes of adult females (Student's t-tests; $p>0.05$ ).

\section{Shell class and moulting}

New shelled (recently moulted) crabs represented $34.6 \%(n=1276)$ of the Lithodes aequispina sampled to $400 \mathrm{~m}$ (Table 4 ). The highest frequency of newshelled (i.e. recently moulted) crabs occurred at $<150 \mathrm{~m}$, with the majority between 101 and $150 \mathrm{~m}$. The trend of increasing proportions of old-shelled crabs with depth was most marked among unparasitized females, although it also occurred among unparasitized males and parasitized crabs. Among unparasitized females, all those with new eggs were shell class 1 whereas all those in the matted setae were shell class 2 .

\section{Reproduction and vertical migration}

Fig. 5 illustrates that female Lithodes aequispina from Alice and Hastings Arms spawn continuously with similar proportions at each stage of female maturity throughout the year. Most of the unparasitized females $(50.0$ to $66.4 \%$ ) were in the matted setae con-

Table 4. Lithodes aequispina. Percentage of shell class 1 (new shelled) individuals among 3687 crabs according to depth (to $400 \mathrm{~m}$ ) in the Portland Inlet system

\begin{tabular}{|c|c|c|c|c|c|c|}
\hline \multirow[b]{2}{*}{ Depth (m) } & \multirow[b]{2}{*}{$\begin{array}{l}\text { Total number } \\
\text { of crabs }\end{array}$} & \multirow[b]{2}{*}{$\begin{array}{l}\text { Number of shell } \\
\text { class } 1 \text { crabs }\end{array}$} & \multicolumn{4}{|c|}{$\%$ of shell class 1 crabs } \\
\hline & & & All crabs & $\begin{array}{l}\text { Unparasitized } \\
\text { males }\end{array}$ & $\begin{array}{l}\text { Unparasitized } \\
\text { females }\end{array}$ & $\begin{array}{c}\text { Parasitized } \\
\text { males \& females }\end{array}$ \\
\hline $50-100$ & 275 & 133 & 48.4 & 38.2 & 58.2 & 58.4 \\
\hline $101-150$ & 241 & 152 & 63.1 & 62.3 & 72.1 & 54.0 \\
\hline $151-200$ & 138 & 52 & 37.7 & 35.1 & 37.0 & 40.4 \\
\hline $201-250$ & 397 & 137 & 34.5 & 40.6 & 20.5 & 45.1 \\
\hline $251-300$ & 529 & 154 & 29.1 & 26.7 & 22.1 & 35.4 \\
\hline $301-350$ & 935 & 276 & 29.5 & 27.8 & 16.4 & 37.8 \\
\hline $351-400$ & 1172 & 372 & 31.7 & 29.4 & 15.0 & 44.0 \\
\hline Totals & 3687 & 1276 & 34.6 & 35.3 & 23.7 & 42.0 \\
\hline
\end{tabular}



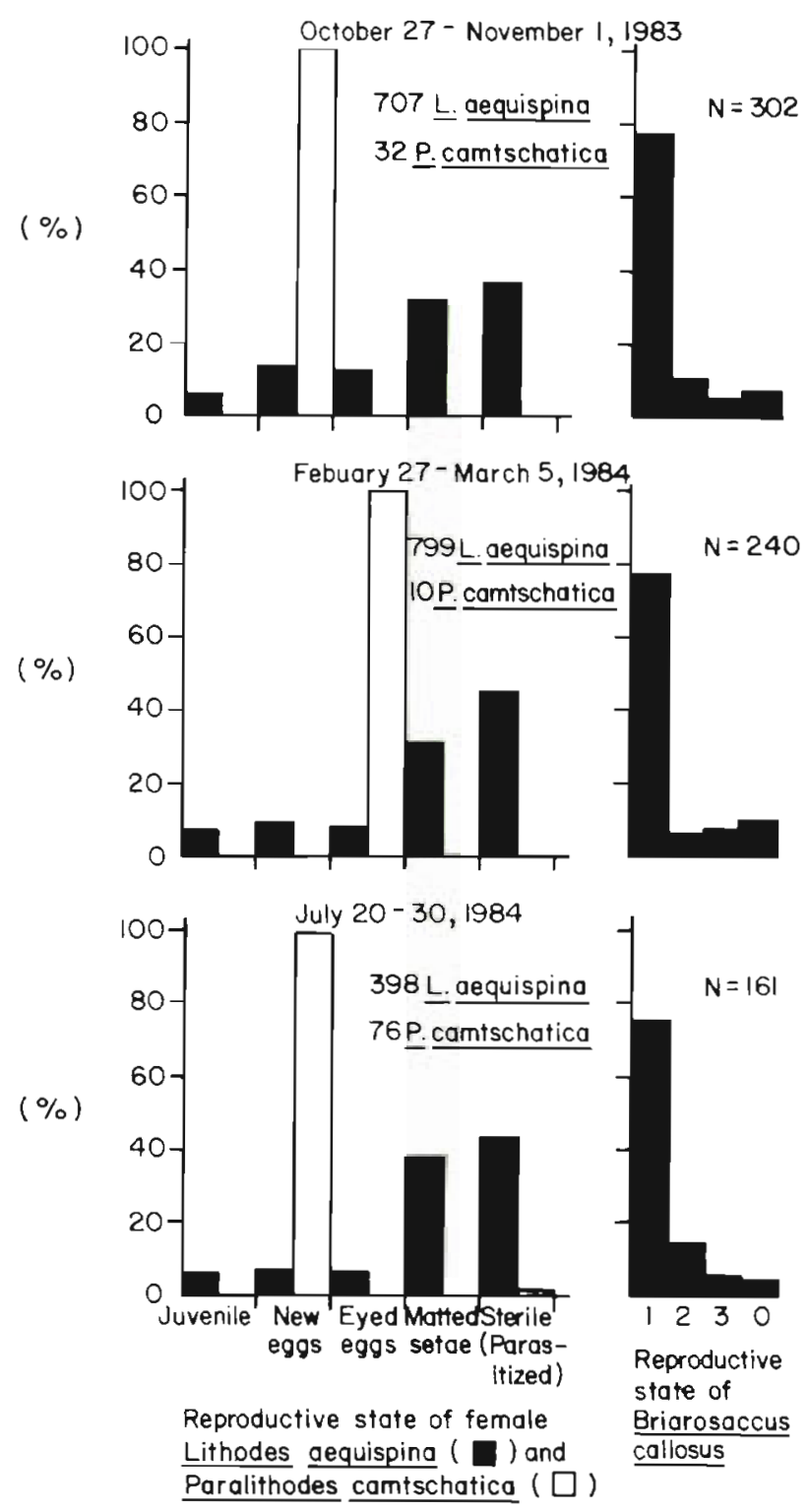

Fig. 5. Reproductive states of 1904 female Lithodes aequispina and 118 female Paralithodes camtschatica, according to the 3 sample periods. Reproductive states of 703 Briarosaccus callosus infecting $L$. aequispina from the 3 sample periods are also illustrated

dition. Briarosaccus callosus, infecting both male and female hosts, also was an asynchronous, continuous spawner as the majority ( $>75.0 \%$ in all samples) of the externae had packed mantle cavities of unhatched eggs at all times of year. Coexisting female Paralithodes camtschatica demonstrated marked peaks in reproductive activity. Within each sample all unparasitized females were in the same maturity stage with probable spring-time (after March) larval release.

The depth distributions (to $400 \mathrm{~m}$ ) of different maturity stages of unparasitized Lithodes aequispina are illustrated in Fig. 6. The highest proportion of juvenile males occurred at 50 to $100 \mathrm{~m}$ and juvenile females at 50 to $150 \mathrm{~m}$. The highest proportion of new-egged females occurred from 101 to $150 \mathrm{~m}$ and eyed egg females from 151 to $200 \mathrm{~m}$. Matted setae females dominated the unparasitized female samples at depths $>200 \mathrm{~m}$.

\section{DISCUSSION}

Lithodes aequispina is a continental shelf-and slopedwelling species (Otto et al. 1983) whose life history characteristics are discussed here for relatively confined, fjord-dwelling populations. These characteristics are related to the deep-water preferences of $L$. aequispina and may be accentuated by confinement in the narrow, steep-walled British Columbia fjords. Life history data on less confined continental slope-dwelling $L$. aequispina from the eastern Bering Sea are forthcoming (D. A. Somerton pers. comm.). Paralithodes camtschatica is an intertidal to continental shelf-dwelling species (see review in Hayes 1983) which, when confined in British Columbia fjords, occupied shallower depths, displayed different reproductive characteristics and had different colouration than coexisting $L$. aequispina. $L$. aequispina was usually a light orange colour overall (similar to the overall bright red characteristic of another deep-water king crab L. couesi (Benedict): Somerton 1981, and in contrast to the dorsal dark burgundy and ventral white colouration of coexisting $P$. camtschatica).

\section{Confinement in fjords}

Among fjords in the Portland Inlet system, Lithodes aequispina occurred as isolated populations. The most isolated, innermost fjords in the system, Alice Arm and Hastings Arm, yielded the most crabs per unit fishing effort although density in the former was appreciably greater than in the latter. Catches were lower in Observatory Inlet and extremely low to nonexistent in the outermost fjords of Portland Inlet and Work Channel. These differing densities of $L$ aequispina may be due to retention of oceanographically confined pelagic larvae.

In a multiple fjord system, Gade \& Edwards (1980) suggested that higher vertical water exchange in the outer basins increases the likelihood of deep water renewal. The similar sill depths $(25$ to $55 \mathrm{~m}$ ) of the 2 innermost fjords and their expected decrease in tidal currents, with increasing isolation causes less energetic flushing, i.e. lower coefficient of turbulent diffusivity (D. J. Stucchi pers. comm.). Observatory Inlet is tidally energetic (Stacey 1984) and experiences more flushing than the innermost fjords. 


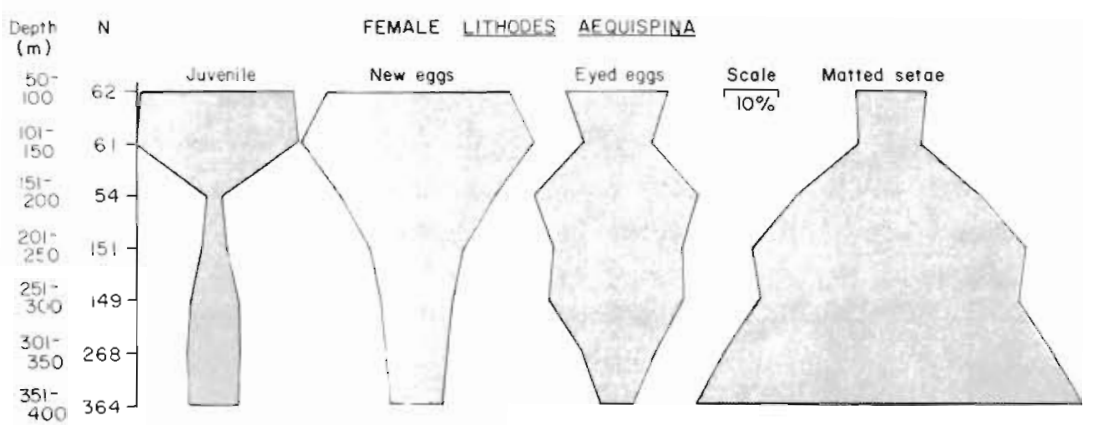

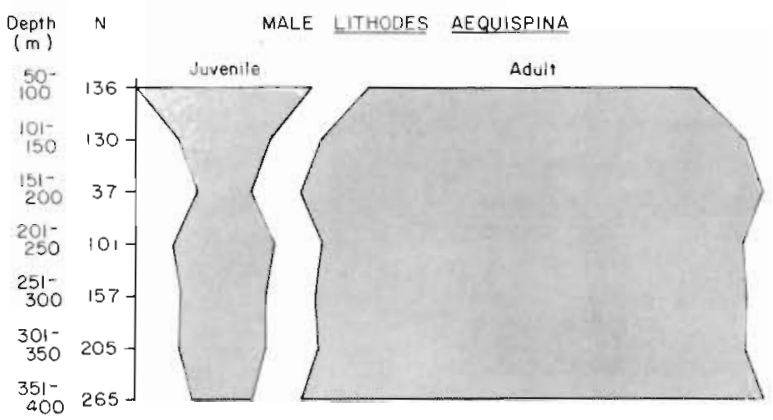

Retention of Lithodes aequispina larvae is enhanced by their hatching at depth (Sloan 1985 and discussed below). Larvae occurring at depth may be moved inland as predicted by the 2-layer model of fjord (estuarine) oceanography. Reliance on this simple model should, however, be cautious when discussing specific fjords as their exchange processes are generally unsteady and can embrace a wide range of time scales' (Farmer \& Freeland 1983). Both Alice Arm (D. J. Stucchi pers. comm. and unpubl.) and Observatory Inlet (Stacey 1984) have characteristics which confound 2-layer flow. The Portland Inlet system as a whole, therefore, possesses complex oceanographic characteristics difficult to predict.

Despite the fairly shallow sills in most of the fjords, all probably experience complete deep-water ( $>$ sill depth) renewal annually, with considerable interannual variations, in different seasons according to fjord (D. J. Stucchi pers. comm.). These renewals may not be important to overall larval retention of Lithodes aequispina or Briarosaccus callosus as both breed continuously, as will be discussed later.

Further evidence for fjordic isolation is provided by the relatively high infection levels of Briarosaccus callosus among Lithodes aequispina from the innermost fjords, where the parasite larvae are broadcast at depth and thus retained similarly to their hosts' larvae (Sloan 1985). Thus, 'larval confinement' sensu Pearson (1980) may have given rise to relatively high numbers of, and parasite infection among, $L$. aequispina in the innermost fjords.

Relatively high Lithodes aequispina numbers in the $\frac{\text { Scale }}{10 \%}$

Fig. 6. Lithodes aequispina. Distribution of proportions of juvenile, egg-bearing and matted-setae females (unparasitized) ( $\mathrm{n}=1109$ ), and of juvenile and adult males (unparasitized) $(n=1031)$ according to depth $(50$ to $400 \mathrm{~m})$ in the Portland Inlet system. Scale bar: $10 \%$ of the female or male unparasitized population

innermost fjords may also relate to exclusion by the sills of predators of planktonic larvae and/or postmetamorphosed crabs. For example, halibut Hippoglossus stenolepis, which can eat adult king crab (Gray 1964), decreased significantly as pot by-catch going inland from Portland Inlet, through Observatory Inlet to Alice and Hastings Arms.

The comparatively large size of Observatory Inlet Lithodes aequispina may indicate less food limitation in its deeps compared to those of the 2 Arms, whose populations are probably denser. Similarly, males from the less dense Hastings Arm population were larger than males from the more dense Alice Arm population.

\section{Reproduction and migration in fjord-dwelling Lithodes aequispina}

Female Lithodes aequispina are continuous, aseasonal spawners with similar proportions of eggbearing individuals found at all times of year. Coexisting female Paralithodes cantschatica, on the other hand, displayed strongly synchronized, seasonal reproduction which is characteristic of the species (Hayes 1983). Briarosaccus callosus infecting $L$. aequispina were continuous spawners. It would be interesting to establish whether $B$. callosus infecting $P$. camtschatica would be influenced by their hosts' more seasonally-cued life history.

The relatively low proportion of egg-bearing females compared to matted setae females at all times suggests that the post-spawned phase may be rela- 
tively long. Somerton \& MacIntosh (1982) found relatively large proportions ( 33 to $52 \%$ of the female population) of 'barren' (matted setae) females to be a persistent feature of an Alaskan blue king crab Paralithodes platypus (Brandt) population. They suggested 'active' (egg-bearing) and 'inactive' (matted setae) phases during the mature life of females. In the western Bering Sea, Sasakawa (1973) proposed that $P$. platypus had a biennial spawning cycle with, however, an egg-bearing stage of 19 mo compared to a much shorter matted setae stage.

There was a marked vertical stratification of Lithodes aequispina in the fjords through migration which I suggest is controlled by sexual maturation among unparasitized crabs and parasitism in the remainder. This migration is likely aseasonal and, therefore, continuous. The entire $L$. aequispina population demonstrated a $1: 1$ sex ratio although segregation among unparasitized crabs occurred according to depth. The greatest proportion of juvenile $L$. aequispina occurred in the shallows (50 to $100 \mathrm{~m}$ ), adult males were slightly deeper, adult females were deeper still and parasitized crabs dominated at $>200 \mathrm{~m}$ (Fig. 3). Relatively shallow distribution of juveniles compared to adults has been reported for some Paralithodes spp. (Somerton 1981) and Lithodes spp. (Stuardo \& Solis 1963, Rodin 1970). I should qualify, however, that numbers of juveniles caught were probably underestimated due to escapement through the pot mesh as also suggested by Somerton (1981) for pot fishing of $L$. couesi. Among only unparasitized $L$. aequispina, juvenile males and females showed similar shallow-water preferences. I suggest that egg-bearing females may migrate downward as incubation progresses through the eyed egg stage to hatching which occurs mostly $>200 \mathrm{~m}$ (Fig. 6). This is opposite to ovigerous females of the deep-water brachyuran Geryon quinquedens Smith which migrate upward to shallower, warmer waters to enhance egg development and hatching' (Haefner 1978).

Female Lithodes aequispina may eventually migrate upwards to moult, mate and extrude eggs in the upper levels $(<150 \mathrm{~m})$. The relatively high proportions of unparasitized adult male and new-egged female $L$. aequispina at $<150 \mathrm{~m}$ suggests this is the depth level at which mating takes place. New-egged females were all shell class 1 (new shelled) which suggests that mating and egg extrusion probably occur soon after moulting as among other lithodid species (Stuardo \& Solis 1963, Somerton \& MacIntosh 1982, Hayes 1983). The relatively high proportion of new shelled males at $<150$ m may mean that males moult before mating, as do Paralithodes camtschatica (Hayes 1983), which is in contrast to L. antarcticus Jacquinot (Stuardo \& Solis 1963) where males apparently delay moulting until after mating. Moulting and mating in relatively shallow water is known for other Lithodes spp. (Stuardo \& Solis 1963, Hiramoto \& Sato 1970, Arnaud et al. 1976). Otto et al. (1983) also reported higher proportions of large male $L$. aequispina at shallower shelf depths than females in the Pribilov district of the eastern Bering Sea. The majority of the unparasitized adult male $L$. aequispina population may reside continually in the upper fjordic depths and not be as migratory as the unparasitized female population.

In summary, the life history pattern for unparasitized Lithodes aequispina in fjords is aseasonal and suggested to include (1) recruitment in the shallows; (2) moulting, mating and egg extrusion slightly deeper, although still relatively shallow; (3) downward migration among incubating females while males tend to remain in the shallows; (4) hatching and larval release at depth; (5) post-spawning recovery in deep water; (6) eventual upward migration by females to mating grounds in shallower fjordic depths. This aseasonal cycle is probably longer than 1 yr. Parasitized male and female $L$. aequispina generally behaved like postspawned females (Sloan 1985) and congregate in deep water; possibly for long periods as the parasites may remain with their hosts, permanently sterilizing them (Bower \& Sloan 1985).

\section{Reproduction and migration in Lithodes spp.}

Reproductive and migratory characteristics reported for 5 Lithodes spp. differ considerably, even among $L$. aequispina from different areas as summarized in Table 5. Although Rodin (1970) suggested L. aequispina was a seasonal (summer) spawner, he proposed that no depth-related migration occurred among $L$. aequispina due to what he considered as an unvarying 'hydrological regime' of their continental slope habitat. Somerton (1981) suggested aseasonal spawning in Lithodes couesi (to $850 \mathrm{~m}$ ) was related to depth. Firstly, seasonal fluctuations of environmental conditions could be less detectable by crabs in deep water. Secondly, and more likely according to Somerton, $L$. couesi larvae may not rise to the euphotic zone and thus not be cued to seasonal shallow water production cycles. On the other hand, both $L$. aequispina and L. longispina (to $900 \mathrm{~m}$ ) in the N. W. Pacific Ocean were claimed to be seasonal, warm month spawners (Table 5). The most shallow-water species, the 'Centolla', L. antarticus from southern Chile, appears to fill a niche similar to that of Paralithodes camtschatica in the northern hemisphere (Table 5). Male L. antarcticus precede females into the shallows $(<10 \mathrm{~m})$ in the warm season (Nov-Dec), incoming females then moult, copulate, extrude eggs and disperse with males off- 
Table 5. Published records of spawning and migration among Lithodes species

\begin{tabular}{|c|c|c|c|}
\hline Species & Author(s) & $\begin{array}{l}\text { Locality; latitude; habitat; } \\
\text { depth (m) }\end{array}$ & Notes on spawning and migration \\
\hline L. aequispina & Hiramoto \& Sato (1970) & $\begin{array}{l}\text { E. coast of central Honshu; } \\
35^{\circ} \mathrm{N} \text {; deep bay; } 400-900\end{array}$ & $\begin{array}{l}\text { Seasonal spawner: spawning occurs from mid Jun } \\
\text { to Oct during which the proportion of adults was } \\
\text { relatively high in shallow water }(400 \text { to } 500 \mathrm{~m}) \text {; } \\
\text { adults then disperse to the depths }\end{array}$ \\
\hline L. aequispina & Rodin (1970) & $\begin{array}{l}\text { Okhotsk Sea; } 53^{\circ}-57^{\circ} \mathrm{N} \\
\text { continental shelf and slope; } \\
250-850\end{array}$ & $\begin{array}{l}\text { Seasonal spawner: between Aug to mid Sept } \\
\text { crabs moult, mate, and spawn; assumed no } \\
\text { seasonal migrations because of suggested } \\
\text { uniformity of oceanographic conditions on the } \\
\text { continental slope }\end{array}$ \\
\hline L. aequispina & This paper & $\begin{array}{l}\text { N. British Columbia; } 55^{\circ} \mathrm{N} \text {; } \\
\text { fjords; } 51-569\end{array}$ & $\begin{array}{l}\text { Aseasonal spawner: unparasitized females spawn } \\
\text { continuously with } 13 \text { to } 26 \% \text { females egg- } \\
\text { bearing at any one time. Incubating females } \\
\text { migrate downwards prior to larval release }\end{array}$ \\
\hline L. antarcticus & Stuardo \& Solis (1963) & $\begin{array}{l}\text { Strait of Magellan; } 53^{\circ} \mathrm{S} \\
\text { deep bay; } 10-200\end{array}$ & $\begin{array}{l}\text { Seasonal spawner: after moulting, mating and } \\
\text { spawning in shallows during the warm months } \\
\text { (Dec to Jan); incubating females and adult males } \\
\text { then disperse to the depths in Feb }\end{array}$ \\
\hline L. couesi & Somerton (1981) & $\begin{array}{l}\text { Gulf of Alaska; } 55^{\circ}-57^{\circ} \mathrm{N} ; \\
\text { tops of seamounts; } 384-850\end{array}$ & $\begin{array}{l}\text { Aseasonal spawner: migration unlikely on the } \\
\text { relatively level seamount tops }\end{array}$ \\
\hline L. longispina & Hiramoto (1974) & $\begin{array}{l}\text { E coast of central Honshu; } \\
35^{\circ} \mathrm{N} \text {; deep bay; } 400-900\end{array}$ & $\begin{array}{l}\text { Seasonal spawner: spawn between mid Aug to } \\
\text { mid Oct, no data on migrations }\end{array}$ \\
\hline L. murrayi & $\begin{array}{l}\text { 'Arnaud (1971); 'Arnaud } \\
\text { et al. (1976); Arnaud \& } \\
\text { Do-Chi (1977) }\end{array}$ & $\begin{array}{l}\text { S. W. Indian Ocean; } 45^{\circ} \mathrm{S} ; \\
\text { continental shelf of oceanic } \\
\text { islets; } 75-187\end{array}$ & $\begin{array}{l}\text { Seasonal spawner: implied from anecdotal } \\
\text { observations that migration to shallows (to } \\
\text { spawn?) occurs in warm months (Dec to Apr) }\end{array}$ \\
\hline
\end{tabular}

shore to deeper water. Indeed, a major problem with the Centolla fishery in Southern Chile is that the fishing season coincides with the species' shallow-water reproductive activities (Campodónico 1981). As with $P$. camtschatica, juvenile $L$, antarcticus recruit and spend the first few years of life in very shallow (2 to $3 \mathrm{~m}$ ) water (Stuardo \& Solis 1963). The proposed seasonal upward migration and reproduction of $L$. murrayi Henderson from various subantarctic sites are strictly anecdotal and should be considered tentative (Table 5).

The reported reproductive differences among Lithodes spp. requires further verification for, despite these differences, the 5 Lithodes spp. in Table 5 show the same important characteristics of relatively few $(<40,000)$, large (mean or median egg size $\geq 2.2 \mathrm{~mm}$ ) eggs (Jewett et al. 1985). On the other hand, the 2 unequivocally seasonal Paralithodes spp. produce many (maxima of 285,000 and 390,000 ), small (<1.2 mm) eggs (Haynes 1968, Sasakawa 1975). Tyler et al. (1982) have shown that among coexisting deepsea $(>2200 \mathrm{~m}$ ) echinoderm species both seasonal and aseasonal reproductive stratagies occurred. All the seasonal species, produced many small eggs. Their larval abundance was suggested to be cued to pulses of organic particles originating from springtime phyto- plankton production in overlying waters. The aseasonal species all produced fewer, but approximately 10 times larger, (more yolky) eggs for 'increased efficiency of reproduction' and 'minimal wastage' before recruitment. The small number and large size $(<28,000 ; \bar{x}=2.4 \mathrm{~mm} ; \mathrm{S}$. C. Jewett et al. 1985 ) of eggs produced by the fjord-dwelling $L$. aequispina further supports my proposal of its continuous reproduction independent of the seasons.

Acknowledgements. I thank S. C. Jewett for field assistance and advice; S. M. C. Robinson for aid with both fieldwork and data analysis; Dr. S. M. Bower for discussions; and Dr. G. S. Jamieson for support. D. J. Stucchi provided and discussed Portland Inlet system oceanographic findings. G. C. Powell and T. Koeneman (Alaska Dept. of Fish and Game) supplied information on Alaskan crabs. The master and crew of 'G. B. Reed provided sound field support throughout. Drs. G. S. Jamieson, L. J. Richards and D. A. Somerton provided rigorous criticism of various drafts. Partial support was provided by the Water Quality Unit, Field Services Branch, Department of Fisheries and Oceans.

\section{LITERATURE CITED}

Armstrong, D. A. (1983). Cyclic crab abundance and relationship to environmental causes. In: Wooster, W. S. (ed.) From year to year. Washington Sea Grant Publication 
WSG-WO 83-3, University of Washington, Seattle, p $102-110$

Arnaud, P. M. (1971). Lithodes murrayi Henderson, 1888 (Crustacea, Decapoda, Anomura) dans les eaux côtieres des îles Crozet (SW de l'océan Indien). Tethys 3: 167-172

Arnaud, P. M., Do-Chi, T (1977). Données biologiques et biométriques sur les lithodes Lithodes murrayi (Crustacea: Decapoda: Anomura) des îles Crozet (SW océan Indien), Mar. Biol. 39: 147-159

Arnaud, P. M., Do-Chi, T., Rannou, M. (1976). Pêches expérimentales de Lithodes murrayi Henderson, 1888 (Crustacea, Anomura) aux îles Crozet (S.W. océan Indien). C.N.F.R.A. (Comité National Français des Recherches Antarctiques, Paris) 39: 27-35

Bower, S. M., Sloan, N. A. (1985). Morphology of the externa of Briarosaccus callosus Boschma (Rhizocephala) and the relationship with its host Lithodes aequispina Benedict (Anomura). J. Parasit., in press

Butler, T. H., Hart, J. F. L. (1962). The occurrence of the king crab, Paralithodes camtschatica (Tilesius), and of Lithodes aequispina Benedict in British Columbia. J. Fish. Res. Bd Can. 19: 401-408

Campodónico, G. (1981). La investigacion biologica y pesquera de los recursos Centolla y Centollon en Chile, sus perspectivas y problemas. Medio Ambiente (Chile) 5: $240-252$

Cimberg, R. L. (1982). Comparative benthic ecology of two southeast Alaskan fjords, Boca de Quadra and Wilson Arm/Smeaton Bay. In: Ellis, D. V. (ed.) Marine tailings disposal. Ann Arbor Science Publishers, Massachusetts, p. 343-356

Farmer, D. M., Freeland, H. J. (1983). The physical oceanography of fjords. Prog. Oceanogr. 12: 147-220

Gade, H. A., Edwards, A. (1980). Deep water renewal in fjords. In: Freeland, H. J., Farmer, D. M., Levings, C. D. (ed.) Fjord oceanography. Plenum Press, New York, p. $453-489$

Gray, G. W. (1964). Halibut preying on large crustacea. Copeia 3: 590

Haefner, P. A. (1978). Seasonal aspects of the biology, distribution, and relative abundance of the deep-sea red crab Geryon quinquedens Smith, in the vicinity of the Norfolk Canyon, western north Atlantic. Proc. natn. Shellfish. Ass. 68: 49-62

Hayes, M. L. (1983). Variation in the abundance of the crab and shrimp with some hypotheses on its relationship to environmental causes. In: Wooster, W. S. (ed.) From year to year. Washington Sea Grant Publication WSG-WO 833. University of Washington, Seattle, p. 86-101

Haynes, E. B. (1968). Relation of fecundity and egg length to carapace length in the king crab, Paralithodes camtschatica. Proc. natn. Shellfish. Ass. 58: 60-62

Hiramoto, K. (1974). Biological notes on an anomuran crab, Lithodes longispina Sakai. Researches on Crustacea No. 6 , Odawara Carcinological Museum, Tokyo, p. 16-24

Hiramoto, K., Sato, S. (1970). Biological and fisheries survey of an anomuran crab, Lithodes aequispina Benedict, off Bōsō Peninsula and Sagami Bay, central Japan. Jap. J. Ecol. 20: 165-170

Hughes, S. E. (1981). Initial U.S. exploration of nine Gulf of Alaska seamounts and their associated fish and shellfish resources. Mar Fish. Rev. 43: 26-33
Jewett, S. C., Sloan, N. A., Somerton, D. A. (1985). Size at sexual maturity and fecundity of fjord-dwelling golden king crab, Lithodes aequispina Benedict, from northern British Columbia. J. Crust. Biol., in press

Levings, C. D., Foreman, R. E., Tunnicliffe, V. J. (1983) Review of the benthos of the Strait of Georgia and contiguous fjords. Can. J. Fish. aquat. Sci. 40: 1120-1141

Otto, R. S., McIntosh, R. A., Stahl-Johnson, K. L., Wilson, S. J. (1983). Report to industry on the 1983 eastern Bering Sea crab survey. North West and Alaska Fisheries Center (Nat. Mar. Fish. Serv.) Processed Rept. 83-18: 1-62

Pearson, T. H. (1980). Macrobenthos of fjords. In: Freeland, H. J., Farmer, D. M., Levings, C. D. (ed.) Fjord oceanography. Plenum Press, New York, p. 453-489

Pickard, G. L. (1961). Oceanographic features of inlets in the British Columbia mainland coast. J. Fish. Res. Bd Can. 20 : 907-999

Rodin, V. E. (1970). New data on the golden king crab. Ryb. Khoz. 46: 11-13. Translated by S. Pearson (1982), Northwest and Alaska Fisheries Center, National Marine Fisheries Service, NOAA, Seattle

Sasakawa, Y. (1973). Studies on blue king crab resources in the western Bering Sea-I. Bull. Jap. Soc. scient. Fish. 39: $1031-1037$

Sasakawa, Y. (1975). Studies on blue king crab resources in the western Bering Sea-III. Bull. Jap. Soc. scient. Fish. 41: $941-944$

Sloan, N. A. (1985). Incidence and effects of parasitism by the rhizocephalan barnacle, Briarosaccus callosus Boschma, in the golden king crab, Lithodes aequispina Benedict, from deep fjords in northern British Columbia, Canada. J. exp. mar. Biol. Ecol. 84: in press

Sloan, N. A., Bower, S. M., Robinson, S. M. C. (1984). Cocoon deposition on three crab species and fish parasitism by the leech Notostomum cyclostoma from deep fjords in northern British Columbia. Mar. Ecol. Prog. Ser. 20: 51-58

Somerton, D. A (1980). A computer technique for estimating the size of sexual maturity in crabs. Can. J. Fish. aquat. Sci. 37: 1488-1494

Somerton, D. A. (1981). Contribution to the life history of the deep-sea king crab, Lithodes couesi, in the Gulf of Alaska. Fish. Bull. U.S. 79: 259-269

Somerton, D. A., MacIntosh, R. A. (1982). Aspects of the life history of the blue king crab (Paralithodes platypus) in Alaska. (Document submitted to the 29th annual meeting of the International North Pacific Fisheries Commission, Tokyo, Japan, October 1982), p. 1-19

Stacey, M. W. (1984). The interaction of tides with the sill of a tidally energetic inlet. J. phys. Oceanogr. 14: 1105-1117

Stuardo, J., Solis, I. (1963). Biometria y observaciones generales sobre la biologia de Lithodes antarcticus Jacquinot. Gayana (Zool.) 11: 1-49

Suzuki, Y., Sawada, T. (1978). Notes on an anomuran crab Lithodes aequispina Benedict, in Suruga Bay. Bull. Shizuoka Pref. Fish. Exp. Stn. 12: 1-10

Tyler, P. A., Grant, A., Pain, S. L., Gage, J. D. (1982). Is annual reproduction in deep-sea echinoderms a response to variability in their environment? Nature, Lond. 300: 747-750

Wallace, M. M., Pertuit, C. J., Hvatum, A. R. (1949). Contribution to the biology of the king crab (Paralithodes camtschatica Tilesius). Fish. Wildl. Serv., U.S. Dept. Commerce, Fish. Leaflet 340: 1-50 